\title{
Aldrin, heptachlor and $\beta$-hexachlorocyclohexane to dairy cows at three oral dosages. 2. Residues post partum in milk and body fat of cows fed on pesticides in the dry period*
}

K. Vreman ${ }^{1}$, L. G. M. Th. Tuinstra ${ }^{3}$, J. Bakker ${ }^{1}$, J. van den Hoek$^{2}$, A. H. Roos ${ }^{3}$, H. de Visser ${ }^{1}$ and J. H. Westerhuis ${ }^{1 * *}$

1 Research Institute for Animal Feeding and Nutrition 'Hoorn', Lelystad, the Netherlands

${ }^{2}$ Laboratory of Animal Physiology, University of Agriculture, Wageningen, the Netherlands

${ }^{3}$ Government Dairy Station, Leyden, the Netherlands

Accepted: 5 October 1977

Key words: cows, dry period, pesticides, milk fat, body fat

\section{Summary}

During the whole dry period 3 groups of 3 Dutch Black Pied and Meuse-RhineIJssel cows each, in a preceding trial also dosed with pesticides during late lactation, received 3 levels each of aldrin, heptachlor and $\beta$-HCH together with concentrate: $0.5 \mathrm{mg}, 1.0 \mathrm{mg}$ or $2.0 \mathrm{mg}$ per cow daily.

Body fat and milk fat samples after calving were taken and analysed for pesticide content.

Aldrin and heptachlor were below the detection limit of $0.01 \mathrm{mg} / \mathrm{kg}$ fat. Contents of $\beta$-heptachlorepoxide were in the most cases below $0.1 \mathrm{mg} / \mathrm{kg}$, even for the highest dosage.

For $\beta-\mathrm{HCH}$ and dieldrin in milk fat a fairly good agreement was found between adjusted values just after calving and values for cows early and late in lactation, both at the end of the dosing period.

A considerable variation in pesticide content of body fat was found, particularly for dieldrin in cows with the highest dosage.

A derivation of maximum tolerable content of pesticide in feed in the dry period is given by using accumulation coefficients and transfer coefficients. The results of both calculation methods agree very well and are compared with legal tolerances for feed.

* Part 1: Neth. J. agric. Sci. 24 (1976) 197-207.

** Present address: Mengvoeder UT Delfia B.V., Maarssen, the Netherlands. 


\section{Introduction}

Transfer of organochlorine pesticides and their metabolites from feed into milk and body fat of dairy cows has often been studied in an earlier or later stage of lactation (Kölling, 1974; Vreman et al., 1976). Also in the dry period, dairy cows and ingest persistent organochlorine pesticides, for example, with roughage or concentrates. Because of the absence of milk production then pesticides can accumulate in the body fat of cows. This may result in a higher contamination of milk than by exposure to the pesticide during lactation (Miller, 1967; Whiting et al., 1973). The present study investigated how far oral administration of aldrin $(1,2,3,4,10,10$ hexachloro-1,4,4a,5,8,8a-hexahydro-exo-1,4-endo-5,8-dimethanonaphthalene), heptachlor (1,4,5,6,7,8,8-heptachloro-3a,4,7,7a-tetrahydro-4,7-methanoindene) and $\beta$-hexachlorocyclohexane ( $\beta$ - $\mathrm{HCH}, \beta$ isomer of $1,2,3,4,5,6$-hexachlorocyclohexane) in the dry period causes accumulation in body fat and contamination of milk fat immediately after calving and during the first weeks of lactation.

\section{Materials and methods}

During the whole period of about 8 weeks, 3 groups of 3 Dutch Black Pied and Meuse-Rhine-IJssel cows each, in a preceding trial also dosed with pesticides during late lactation (Vreman et al., 1976), received 3 levels of aldrin, heptachlor and $\beta$-HCH together with concentrate.

The dosages per cow were $0.5,1.0$ and $2.0 \mathrm{mg}$ per day of each pesticide for

Table 1. Summary of experimental conditions.

\begin{tabular}{|c|c|c|c|}
\hline Group & 1 & 2 & 3 \\
\hline Number of cows & 3 & 3 & 3 \\
\hline \multicolumn{4}{|l|}{ Body weight $(\mathrm{kg})$} \\
\hline \multirow{2}{*}{$\begin{array}{l}\text { - just after calving, mean } \\
\text { range }\end{array}$} & 649 & 570 & 559 \\
\hline & $630-667$ & $570-582$ & $502-608$ \\
\hline - 1 month after calving, mean & 599 & 532 & 528 \\
\hline \multirow{2}{*}{$\begin{array}{c}\text { range } \\
\text { Milk fat production (g/day), mean }\end{array}$} & $594-603$ & $513-567$ & $482-564$ \\
\hline & 1060 & 1159 & 891 \\
\hline range & $971-1129$ & $1124-1185$ & $815-951$ \\
\hline \multicolumn{4}{|l|}{ Intake of hay $(\mathrm{kg} /$ day $)$} \\
\hline - dry period & 8 & 8 & 8 \\
\hline $\begin{array}{l}\text { - first } 5 \text { weeks after parturition } \\
\text { Content of dry matter in hav ( } \%)\end{array}$ & 7 & 7 & 7 \\
\hline \multirow{2}{*}{$\begin{array}{l}\text { Content of dry matter in hay }(\%) \\
\text { Intake of concentrate }(\mathrm{kg} / \text { day) }\end{array}$} & 87 & 87 & 87 \\
\hline & & & \\
\hline - dry period & 1 & 1 & 1 \\
\hline $\begin{array}{l}\text { - first } 5 \text { weeks after parturition } \\
\text { Content of dry matter in concentrate (\%) }\end{array}$ & 9 & 10 & 8.5 \\
\hline Content of dry matter in concentrate $(\%)$ & 87 & 87 & 87 \\
\hline \multirow{2}{*}{$\begin{array}{l}\text { Dosage of each pesticide (mg/day) } \\
\text { Total dose of each pesticide (mg) }\end{array}$} & 0.5 & 1.0 & 2.0 \\
\hline & & & \\
\hline $\begin{array}{l}\text { - mean } \\
\text { - range }\end{array}$ & 26 & 56 & 87 \\
\hline - range & $22-29$ & $46-61$ & $50-130$ \\
\hline
\end{tabular}




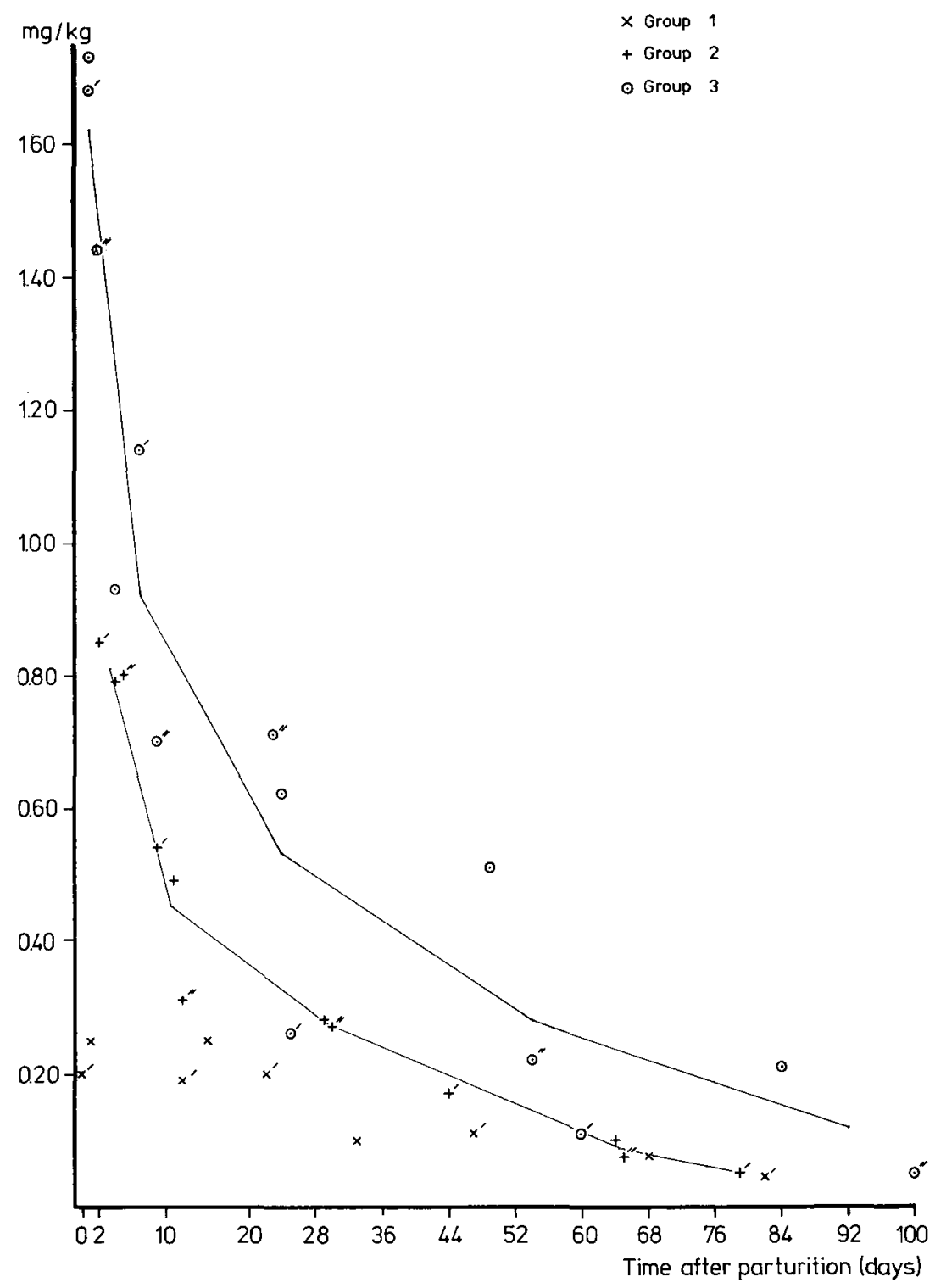

Fig. 1. Content of $\beta-\mathrm{HCH}$ in milk fat of cows given three levels. (The three cows of each group are distinguished by accents over the data points.)

Groups 1, 2, and 3, respectively. At parturition, administration of pesticides was terminated. Because the date of parturition could only roughly be predicted, the dry period per cow varied considerably, resulting in large differences in total dose of pesticides for cows within a group (Table 1). 
After calving, milk yield was recorded weekly on 3 consecutive days for 5 weeks. Dosing method, sampling of milk for estimation of fat and pesticide, and analytical methods were as described before (Vreman et al., 1976). Samples of subcutaneous body fat from the flank of all cows were taken on 18 February 1975 close to calving and 5 weeks later.

Because of variation in the real date of calving between cows, the date of taking a biopsy sample is expressed as number of days after parturition (minus means before). The first date of sampling ranged from 9 days before parturition for the second cow of Group 3 to 15 days after parturition for the first cow of Group 3.

Details of the cows, of the rations and of the pesticides are summarized in Table 1.

\section{Results and discussion}

Milk fat

Contents of $\beta-\mathrm{HCH}$ and dieldrin in milk fat are shown in Fig. 1 and 2. Aldrin and

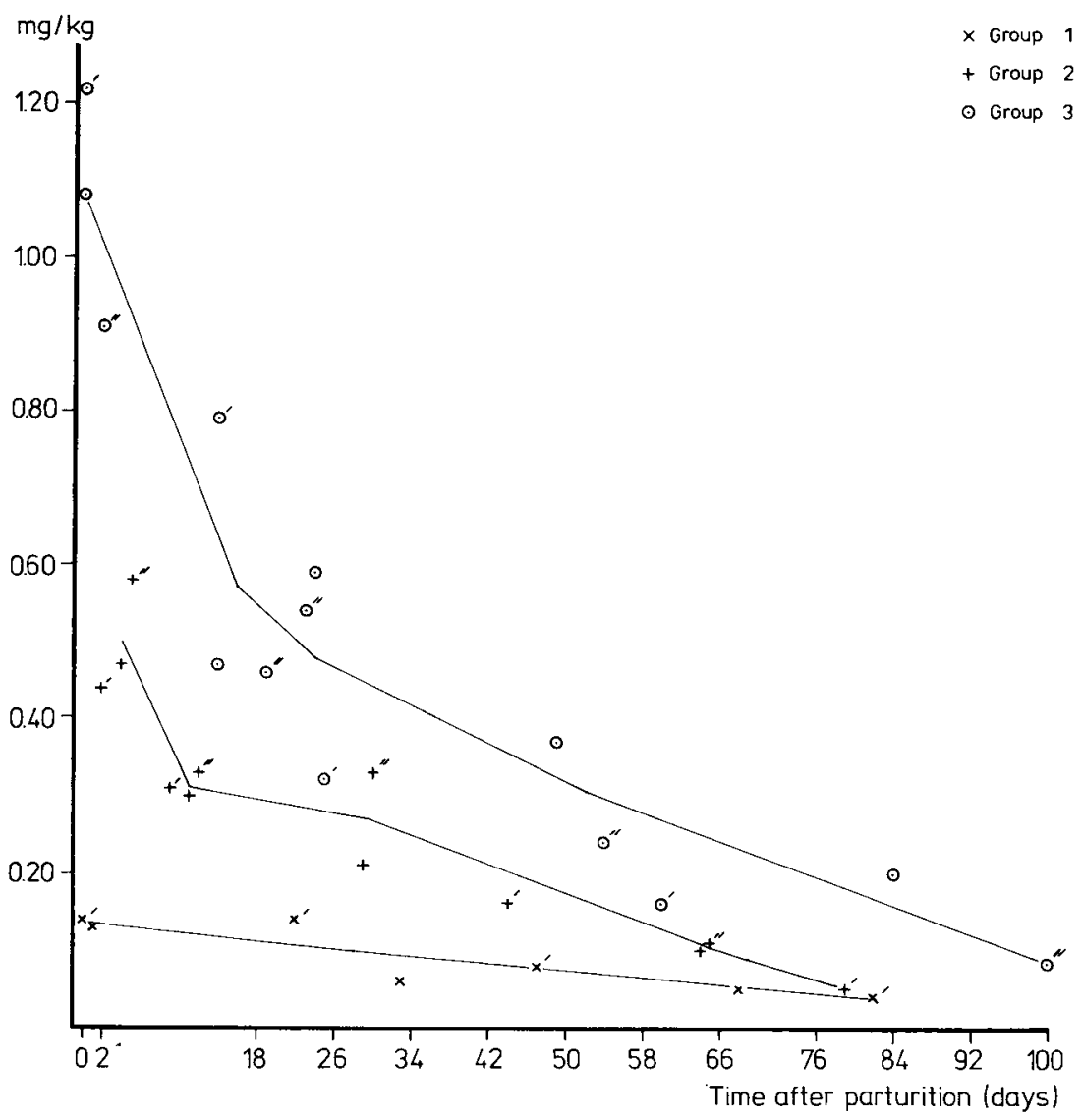

Fig. 2. Content of dieldrin in milk fat of cows given three levels. 
Table 2. Average contents of $\beta-\mathrm{HCH}$ and dieldrin in $\mathrm{mg} / \mathrm{kg}$ in milk fat and body fat at the end of the dosing period of cows late and early in lactation (data from Part 1 ) and just after calving. For explanation of adjusted value see text.

\begin{tabular}{|c|c|c|c|c|c|c|}
\hline \multirow[b]{2}{*}{ Group } & \multicolumn{3}{|c|}{$\beta-\mathrm{HCH}$} & \multicolumn{3}{|c|}{ Dieldrin } \\
\hline & 1 & 2 & 3 & 1 & 2 & 3 \\
\hline \multicolumn{7}{|l|}{ In milk fat } \\
\hline - early in lactation & 0.34 & 0.67 & 1.18 & 0.28 & 0.48 & 0.80 \\
\hline - late in lactation & 0.28 & 0.58 & 1.05 & 0.22 & 0.50 & 0.99 \\
\hline - just after calving & 0.23 & 0.81 & 1.62 & 0.14 & 0.50 & 1.07 \\
\hline - adjusted & 0.19 & 0.67 & 1.38 & 0.10 & 0.39 & 0.87 \\
\hline \multicolumn{7}{|l|}{ In body fat } \\
\hline - early in lactation & 0.17 & 0.41 & 0.61 & 0.16 & 0.35 & 0.63 \\
\hline - late in lactation & 0.08 & 0.28 & 0.74 & 0.09 & 0.24 & 0.44 \\
\hline - just after calving & 0.11 & 0.38 & 0.82 & 0.12 & 0.37 & 0.80 \\
\hline
\end{tabular}

heptachlor in milk fat were below the detection limits of $0.01 \mathrm{mg} / \mathrm{kg}$ fat. Contents of $\beta$-heptachlorepoxide just after calving were below $0.1 \mathrm{mg} / \mathrm{kg}$, even for the highest dosage (Table 3). The contents of $\beta-\mathrm{HCH}$ and dieldrin in milk fat showed a similar trend as for cows in late and early lactation (Vreman et al., 1976), in that the contents decreased with time after dosing with pesticides was discontinued. In Table 2, the contents of $\beta$ - $\mathrm{HCH}$ and dieldrin in milk fat immediately after parturition as found in this trial are compared with contents for cows early and late in lactation as found as in the earlier trials.

The values after parturition do not represent only the effect of dosing during the dry period, because the cows had also been dosed with pesticides late in lactation. As a result of this dosing, milk fat produced just before the start of the dry period contained $\beta-\mathrm{HCH}$ and dieldrin: for Group 1 an average background content in milk fat of 0.09 and $0.08 \mathrm{mg} / \mathrm{kg}$, respectively, was found; 0.28 and $0.21 \mathrm{mg} / \mathrm{kg}$ for Group 2, and 0.48 and $0.39 \mathrm{mg} / \mathrm{kg}$ for Group 3. As found in a trial still to be published (Vreman \& Poortvliet), the contents of these pesticides in milk fat just after calving were half of those in milk fat at the end of the preceding lactation. To find the effect of dosing with pesticides during the dry period, the values given in Table 2 should be adjusted by half of the background contents at the end of the preceding lactation (Table 2). A fairly good agreement was found between adjusted values just after calving and values for cows early and late in lactation, both at the end of the dosing period. In both trials, the total doses of pesticides were of the same order.

In the first weeks of lactation, the pesticide content of milk fat of cows in Groups 2 and 3 declined rapidly. The content of $\beta$-HCH in milk fat was halved within about 2 weeks. For Group 1, the rate of decline of $\beta-\mathrm{HCH}$ was much slower. For this group, halving of the initial value took about 4 weeks.

The rate of decline for dieldrin was slower than that for $\beta$-HCH. The value was halved after 3 weeks for the Groups 2 and 3 and after about 5 weeks for Group 1. This slower decline at a lower dosage was found also for DDT (Whiting et al., 1973). 
After the first 2-3 weeks, the reduction in pesticide content slowed down and the time taken for a further halving was roughly double.

Body fat

Contents of $\beta-\mathrm{HCH}$ and dieldrin in body fat are presented in Fig. 3 and 4 . Contents of $\beta-\mathrm{HCH}$ in body fat near parturition were always less than in milk fat. A considerable variation in pesticide content of body fat was found, particularly for dieldrin in cows with the highest dosage. The dieldrin contents 5 weeks later were hardly different for any group. The $\beta$ - $\mathrm{HCH}$ contents tended to decrease only after the highest dosage.

Derivation of maximum tolerable content of pesticide in feed in the dry period

The daily administered dosages of pesticides used in our trial can be expressed as contents in the whole ration, as given in Table 1 . These contents can be used to calculate an accumulation coefficient, i.e. the pesticide content in milk fat just after calving divided by the pesticide content in the feed of the dry period. The highest accumulation coefficients for the Groups 1,2 and 3 are for $\beta$-HCH 3.78, 6.39 and 6.84 , respectively, and for dieldrin $1.80,4.14$ and 4.41 (Table 3 ).

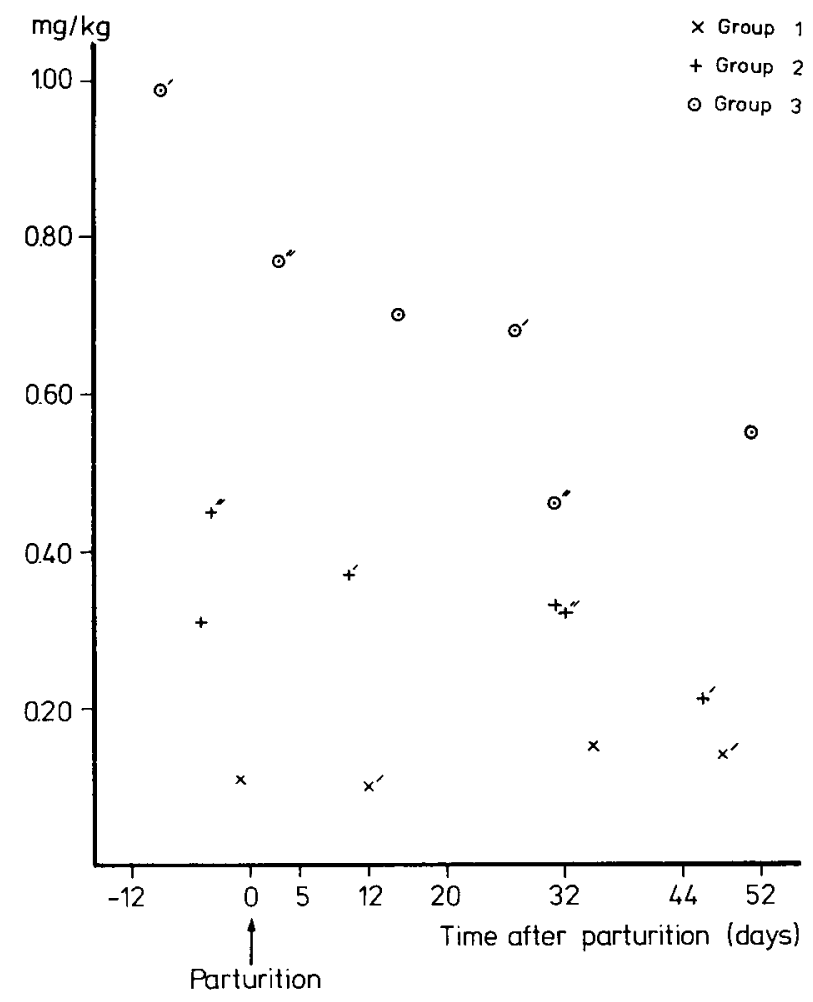

Fig. 3. Content of $\beta-\mathrm{HCH}$ in body fat of cows given three levels. 


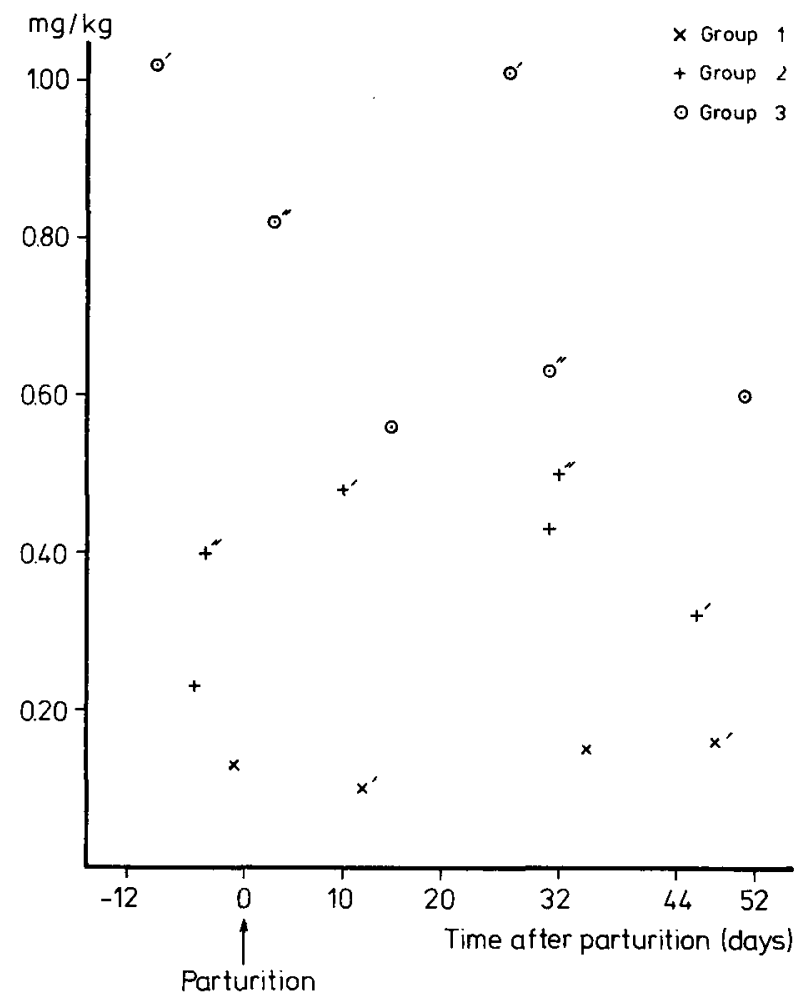

Fig. 4. Content of dieldrin in body fat of cows given three levels.

In Table 3 are also given the calculated transfer coefficients, defined as the proportion of oral pesticide intake per cow per day recovered per day in milk at the end of the dosing period, in this case just after parturition. These transfer coefficients are considerably higher than those found in earlier trials for cows early in lactation (Vreman et al., 1976).

The transfer coefficients for $\beta$ - $\mathbf{H C H}$ and dieldrin of cows of Group 1 are about half of those of cows in Group 2. This result cannot be explained, but may be due to scatter.

The differences between cows within a group are considerable and largely due to variation in milk fat production and in length of the dosing period.

The maximum tolerable pesticide content in the daily ration can also be derived from the maximum tolerable pesticide content in milk fat by using the formula given in Part 1 (Vreman et al., 1976).

The results of using both types of coefficients are summarized in Table 4 and agree very well. The values for Group 1 are higher, because of lower accumulation coefficient and transfer coefficient (Table 3).

If we use other safety factors than 2 , the maximum tolerable content of pesticide in the ration has to be changed accordingly. 
K. VREMAN ET AL.

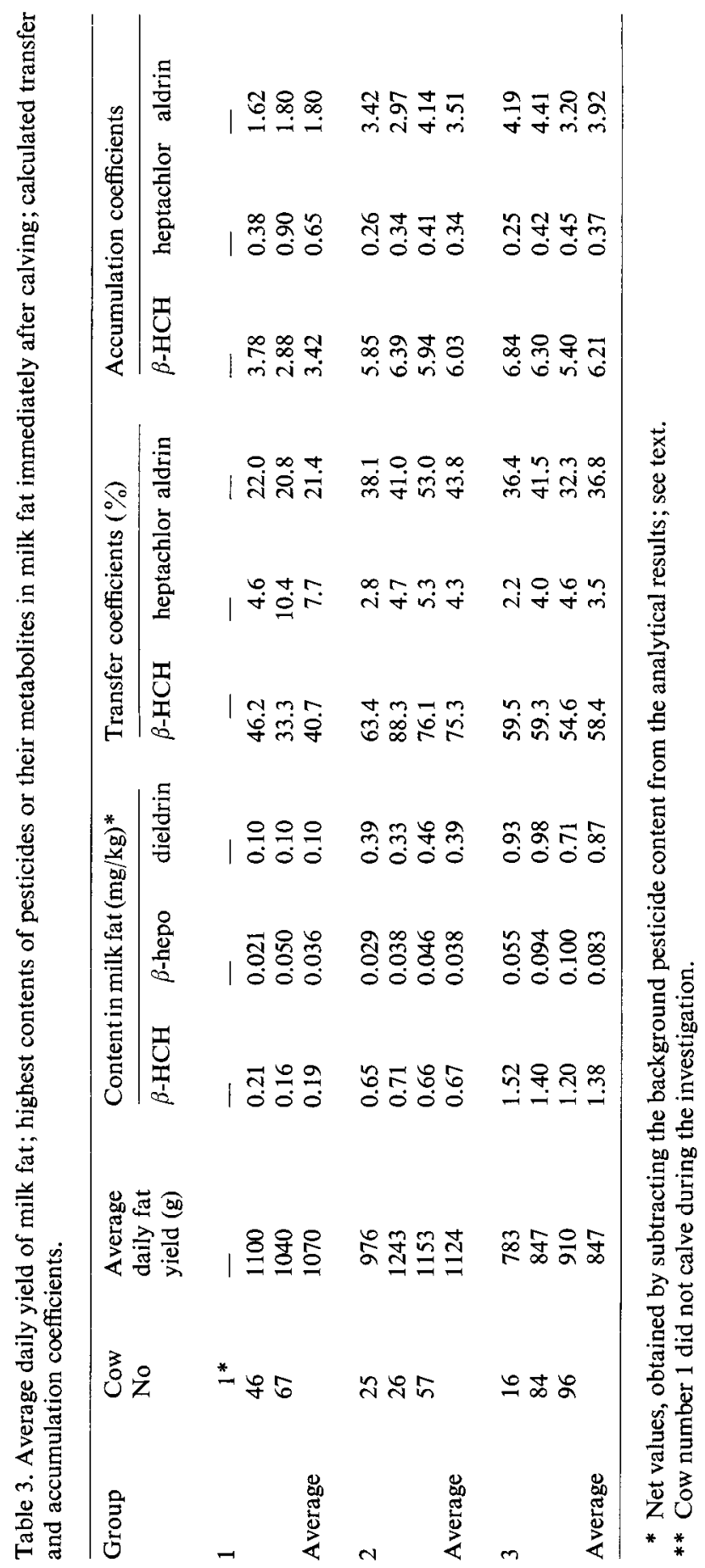


Table 4. Maximum tolerable pesticide content* in the daily ration $(\mathrm{mg} / \mathrm{kg})$ derived ${ }^{* *}$ from tolerances in milk fat.

\begin{tabular}{|c|c|c|c|c|c|c|}
\hline \multirow[t]{2}{*}{ Pesticide } & \multirow[t]{2}{*}{ Type of calculation } & \multicolumn{3}{|c|}{ Group } & \multicolumn{2}{|c|}{ Tolerances } \\
\hline & & 1 & 2 & 3 & milk & feed \\
\hline \multirow[t]{2}{*}{$\beta-\mathrm{HCH}$} & accumulation coeff. & 0.007 & 0.004 & 0.004 & $0.05 * *$ & 0.02 \\
\hline & transfer coeff. & 0.006 & 0.004 & 0.003 & & \\
\hline \multirow[t]{2}{*}{ Aldrin } & accumulation coeff. & 0.042 & 0.018 & 0.017 & 0.15 & 0.02 \\
\hline & transfer coeff. & 0.038 & 0.016 & 0.015 & & \\
\hline \multirow[t]{2}{*}{ Heptachlor } & accumulation coeff. & 0.083 & 0.181 & 0.167 & 0.15 & 0.03 \\
\hline & transfer coeff. & 0.075 & 0.163 & 0.148 & & \\
\hline
\end{tabular}

* Adjusted to $12 \%$ moisture.

** Derived by using the highest accumulation and transfer coefficient for each group of 3 cows and by using a safety factor of 2 .

*** Used by the authors as an example for calculation.

The result for aldrin is in agreement with regulations from the Board for Animal Feedingstuffs (Produktschap voor Veevoeder, last column), the result for heptachlor is higher than the maximum tolerable content given by the Board. Heptachlor can be converted to $\beta$-heptachlorepoxide. The transfer for this metabolite from feed into milk is much higher than for heptachlor itself. A transfer coefficient as high as 39.6 has been reported (Hascoet, 1970) for the epoxide. This high transfer coefficient for $\beta$-heptachlorepoxide leads to a maximum tolerable content in the ration of about $0.01 \mathrm{mg} / \mathrm{kg}$. The regulations from the Produktschap voor Veevoeder do not list a tolerance for $\beta$-HCH in the feed. The Council of the European Communities (EEC doc 903/VI/75) has proposed a provisional maximum content for single feedstuffs of $0.02 \mathrm{mg} / \mathrm{kg}$, which is much higher than the calculated value given in Table 4.

\section{Acknowledgments}

The authors are grateful to the following: Mrs S. M. Spaas-Neuteboom for her great amount of analytical work; Mr G. Dam for feeding the cows and collecting the milk samples; Dr Ir A. J. H. van Es for advice and suggestions; Mr H. J. Mol for his encouragement in arranging this trial and Mr J. C. Rigg for checking the English.

\section{References}

E.E.G. Arbeitsgruppe Pflanzenschutzrecht Untergruppe Rückstände von Schädlingsbekämpfungsmitteln. Document 903/VI/75 - D 30-1-75.

Hascoet, M., 1970. Les résidues de pesticides dans les produits laitiers. PO-LAIT 59: 521-534.

Kölling, K., 1974. Der 'Carry Over' chlorierter Kohlenwasserstoffe aus dem Futter in Lebensmittel tierischer Herkunft. Ubers. Tierernähr. 2: 291-312.

Miller, D. D., 1967. Effect of thyroprotein and a low-energy ration on removal of DDT from lactating dairy cows. J. Dairy Sci. 50: 1444-1447.

Produktschap voor Veevoeder, 's-Gravenhage. Bijlage bij Besluit Veevoeder: ongewenste stoffen en produkten 1975. 
Vreman, K., L. G. M. Th. Tuinstra, J. van den Hoek, J. Bakker, A. H. Roos, H. de Visser \& J. H. Westerhuis, 1976. Aldrin, heptachlor and $\beta$-hexachlorocyclohexane to dairy cows at three oral dosages. 1. Residues in milk and body fat of cows early and late in lactation. Neth. J. agric. Sci. 24: 197-207.

Whiting, F. M., W. H. Brown \& J. W. Stull, 1973. Pesticide residues in milk and in tissues following long, low 2.2 - bis (p. chlorophenyl) - 1, 1, 1 - trichloroethane intake. J. Dairy Sci. 56: $1324-1328$. 